\title{
Essential Newborn Care in the Municipality of Kara (North Togo) in 2019
}

\section{Segbedji KAR ${ }^{1 *}$, Tchagbele O-B $B^{1}$, Talboussouma $S^{1}{ }^{1}$, Agrigna $H^{1}$, Kombieni $K^{1}$, Atakouma $Y D^{2}$ and Azoumah K $D^{1}$}

${ }^{1}$ Department of Pediatrics FSS, University of Kara, Togo

${ }^{2}$ Department of Pediatrics FSS, University of Lomé, Togo

*Corresponding author: Segbedji Kokou Agbékogni Réné, Department of Pediatrics FSS, University of Kara, Togo, Tel: 00228-90-10-56-63

\begin{abstract}
Introduction: Every newborn at birth needs an adequate essential care provided by qualified personnel in order to reduce neonatal morbidity and mortality. The aim of this study was to evaluate the practice of essential newborn care $(E N C)$ in two tertiary hospitals in the City of Kara (North Togo).

Methodology: It was a prospective and descriptive study about ENC, carried out from March $1^{\text {st }}$ to May $30^{\text {th }}$ of 2019 The study was focused on newborns after their immediate vaginal delivery, their mothers and the hospital personnel's who provided care for them at the hospitals ( $\mathrm{CHU}$ and $\mathrm{CHR}$ ) of Kara.

Results: The results indicate that $4.0 \%$ of skin-to-skin contact was performed; $100 \%$ of immediate drying at birth was carried out; $100 \%$ of the umbilical cord section was well done; $100 \%$ of vitamin K1 well administered; $100 \%$ of eye care was given, $49 \%$ of early breastfeeding was performed, $85 \%$ of the first bath was done 6 hours after childbirth and $15 \%$ between 7 and 24 hours of the newborns.
\end{abstract}

Conclusion: Every hospital center has its own way of practicing ENC in the City (Kara). However, in order to decrease newborn mortality, the ENC practices need to be improved in every hospital center in the city.

\section{Keywords}

Essential care, Newborns, Childbirth, Neonatal mortality

\section{Introduction}

The Essential newborn care (ENC) is a best strategy to improve newborn health and survival through a range of interventions performed immediately after birth, as well as during the postnatal period [1]. One baby dies every two minutes in the WHO Western Pacific Region [2]. The majority of neonatal deaths occur in the first few days of life, most of the time from causes that are preventable. The high rates of newborn morbidity and mortality are linked to inappropriate hospital and community practices that are currently seen across the Region. In addition, there is a gap between maternal and child care in which newborn care falls [2].

According to WHO in 2019, around 2.4 million newborns died worldwide, mostly in developing countries [3]. A quarter of these neonatal deaths occur in Africa where only $11 \%$ of the world's population lives. Two thirds of neonatal deaths in Africa are preventable with essential interventions for mothers and newborns; indeed, there are simple, safe and effective actions which can be done by health workers to prevent or treat most of the problems that can cause neonatal death [1]. A study from rural communities in six countries reveals that the rate of neonatal death in the 7 days after birth did not decrease after the introduction of Essential Newborn Care training of community-based birth attendants [4]. However training in basic neonatal care may have a role in improving perinatal outcomes in the developing world but more work is needed to further reduce perinatal mortality [4].

In Togo, the neonatal mortality rate fell considerably from 1998 to 2013 (40\% to $27 \%)$ due to various

Citation: Segbedji KAR, Tchagbele O-B, Talboussouma SM, Agrigna H, Kombieni K, et al. (2021) Essential Newborn Care in the Municipality of Kara (North Togo) in 2019. Int J Pediatr Res 7:080. doi. org/10.23937/2469-5769/1510080

Accepted: October 06, 2021: Published: October 08, 2021

Copyright: (c) 2021 Segbedji KAR, et al. This is an open-access article distributed under the terms of the Creative Commons Attribution License, which permits unrestricted use, distribution, and reproduction in any medium, provided the original author and source are credited. 
interventions, the neonatal mortality remains one third in the infant and child mortality (32.3\%) [5].

Since 2012, the Ministry of Health has therefore undertaken, with the support of UNICEF to strengthen the supply of ENCs, including resuscitation care using the "help babies breathe (HBB)" method. Series of strengthen health professionals'skills have been spread in health centers of all country [6].

Most neonatal deaths occur during the critical phase of the first week of life. These deaths are the result of poor health and poor nutritional status of the mother, combined with insufficient care before, during and after childbirth [1]. Unfortunately, this problem remains unrecognized or worse considered inevitable in many societies. Recognizing the heavy burden that poor maternal and newborn health places on the development capacity of individuals, communities and societies, world leaders reaffirmed their commitment to mothers and children by adopting specific goals and targets aimed at reducing maternal and infant mortality within the framework of the Millennium Declaration [1].

In order to appreciate infant interventions at birth and professionals' skills in the two tertiaries hospitals of Kara, we have undertaken this study in Kara to evaluate the practice of ENC in delivery room. In a specific way, it was questions of describing the knowledge of the personnel of the maternity on the ENC; to describe the practice of this care and determine the factors that limit their practice.

\section{Patients and Methods}

This cross-sectional study was carried out from March $1^{\text {st }}$ to May $30^{\text {th }}$, of 2019 (3 months) in the maternity wards of the University Hospital of Kara ( $\mathrm{CHU}-\mathrm{K}$ ) and the Regional Hospital of Kara (CHR-K).

We have incorporated all the newborns except the ones from C-Section (resuscitated or not), the mothers who agreed to be part of the study and health workers who assisted the childbirth.

We used a non-probabilistic random type to collect data. An individual interview with each newborn mother and with the health provider. We also used the observations and findings of the investigator concerning the delivery room, the equipment and the practice of essential care at birth.

The practices and skills assessed are: Prevention of hypothermia, the administration of vitamin $\mathrm{K}$ and eye drops and skin-to-skin practice after delivery. Aspects related to reception are also assessed.

Authorization was obtained from the director of the National School of Midwives in Kara. The letters of information were sent to the administrative and health authorities of the two hospitals to request their authorization. Informed and free consent of participants have been obtained. Anonymity was respected and the results were kept confidential.

The data were entered and analyzed using Excel and Epi Info 3.5.1 software.

\section{Results}

The study involved 100 mother-newborn couples resulting from vaginal deliveries. We involved in the study 27 midwifes from the two hospitals.

\section{Data on the mother}

The mothers were aged between 18 and 35-yearsold in $89.0 \%, 6.0 \%$ between 15 and 17-years-old and $5.0 \%$ aged 36 and over. They were illiterate in 35\% of cases.

The mothers were first time mothers (54\%), pauciparous (31\%) and multiparous (15\%).

The prenatal analysis was done by $92 \%$ of the mothers; the remaining $8 \%$ didn't honor due to lack of financial means.

Mothers had performed less than 4 antenatal consultations (ANC) in 19\% of cases, 4 ANC in 38\% of cases and 5 ANC and more (15\%). Among mothers, $90.0 \%$ were aware of the value of prenatal visits. The benefit of ANCs was better mother-child followup $(27 \%)$, prevention of pregnant diseases (10\%), protection of pregnancy (12\%), and prevention of pregnancy complications (8\%).

The poor reception (21\%) and the lack of explanation ofthe care to be provided (2\%) were the main complaints made against health workers.

The benefits of childbirth in a health facility according to mothers were better managed (81\%) of avoidance of complications and (9\%) of lower risk.

Childbirth in a health facility is identical to the one at home according to five (05) of the mothers and three (03) others believe that it was not necessary to come to a health facility.

\section{Essential newborn care practices}

General data: No clothes were brought for the newborn in 16 cases, because half of them (mothers) did not know they were coming to give birth and the other half believed that bringing cloth was not necessary.

$40 \%$ of mothers in some cases knew the correct positioning of the baby at the breast and $55 \%$ of them were also satisfied with the services offered.

Regarding the proposals for improving services, $8.2 \%$ proposed to improve the reception of clients without distinction, $8.2 \%$ said to encourage women during delivery, $8.2 \%$ suggested that the staffs need to stopper forming certain abnormal acts when they are in pain, $7.0 \%$ said they had empathy for the clients, $7 \%$ wanted 
to be explained more about the birth plan. Others said to reduce the cost of products and care, act gently, speak to clients with respect and consideration, listen to parturient a little bit and share the sex of the child with them.

To perform the birth, (88\%) of the medical personnel washed their hands, (100\%) wore a clean gown, (68\%) used aprons and (100\%) also utilized sterile gloves.

Newborn's Information: $56.0 \%$ were male, $49 \%$ weighted between 2500 and 3000 grams and 15\% weighted less than 2500 grams.

Newborns had Apgar scores between 8 and 10 in $83 \%$ of cases at the $1^{\text {st }}$ minute and $100 \%$ of cases at the $10^{\text {th }}$ minute.

$23 \%$ of the newborns were resuscitated and $4 \%$ were brought into skin-to-skin contact with their mothers. $100 \%$ were dried immediately and provided with protection against cold (100\%). Correct cord section (100\%) and hourly latching (49\%) were performed.

The newborns had normothermia (86\%), normal sucking reflex (93\%), and good skin color (82\%). As anomalies, prematurity (11\%) and inhalation of amniotic fluid (49\%) were found.

All newborns observed had received eye care as well as vitamin $\mathrm{K} 1$ in both hospitals.

The first bath had given to newborns after the sixth hour in $85 \%$ of cases.

Delivery room data: The delivery conditions were good. Delivery rooms were closed (86\%), clean (100\%), well-lit (100\%), no drafts (50\%), and kept warm (50\%).

The container for dirty linen, clean and sterile materials, the thermometer, the ventilation bag in good condition, and the Pinard stethoscope were fully available (100\%). The rest of the materials for the ENCs were partially available: Materials collected before childbirth (72\%), clean towels and clean water (60\%), the vacuum cleaner (50\%), eye drops (50\%), vitamin K1 (50\%) and a clock (50\%).

Data on the person attending the birth and the person providing care for the newborns: During our survey, all deliveries were made by midwives. The ENCs were given to the newborns after the cord was cut by birth attendants and midwives.

Knowledge and practice of health workers in the care of the newborn: Providers (100\%) who took care of the newborn felt that the benefit of drying the newborn immediately after childbirth is to protect it against hypothermia and that the newborn's first bath is done 6 hours after birth and early breastfeeding of the newborn within 30 minutes of childbirth.

All providers (birth attendants, midwives) were aware of the value of administering vitamin $\mathrm{K} 1$, which is to protect the newborn against neonatal hemorrhage. They also knew the value of eye drops, which is to protect the newborn against eye infection. They had not reported any difficulties in the providing of ENCs.

\section{Discussion}

\section{Socio-demographic characteristics of mothers of newborns}

The mothers were literate in $35 \%$ of cases. This rate is lower than the $98.66 \%$ reported by Moussa Kamissoko in Mali [7]. The low socio-economic level and understanding of some advice during antenatal care probably influenced our results. A study by Zafar and al on factors influencing the use of antenatal care services reported that literate mothers used antenatal care services more than those with no formal education [8]. The best way to help mothers to use medical facilities is to improve their education level.

\section{Data on the care provider (midwife) and the newborn}

In our study, $12 \%$ of providers did not wash their hands before wearing the gloves for childbirth. Hand washing must be systematic before any medical procedure. This finding can be the cause of nosocomial infections for both the mother and the newborn during and after birth.

$68 \%$ of providers wore an apron during childbirth. The study carried out in Senegal in 2005 found that wearing an apron and a gown protects medical personnel against microorganisms, the skin and clothing of the provider from any contact with blood and 'other liquids [9].

Skin-to-skin contact was only made in $4 \%$ of newborns. Our rate is much lower than a study conducted in eastern Uganda which found 80.7\% [10]. The best practice to prevent newborn mortality is to promote skin-to-skin practice just after birth especially for newborn less than 2500 g. Recent study reveals that among infants with a birth weight between 1.0 and $1.799 \mathrm{~kg}$, those who received immediate kangaroo mother care had lower mortality at 28 days than those who received conventional care with kangaroo mother care initiated after stabilization $[11,12]$.

Immediate drying was performed in $100 \%$ of the newborns. This rate is higher than that of Diarra S where only $13 \%$ have performed immediate drying. To prevent overcooling, the newborn should be dried as soon as he was born [13]. This result is due to the protocol in the delivery room where the first step is to dry the newborn.

In our study, it appears that no newborn child benefited from wearing a cap. A study conducted in Senegal in 2005 found that after birth the newborn cools very quickly, and hypothermia increases the risk of illness and death. So temperature maintenance is an extremely important aspect of all newborn care at 
birth. The newborn should be covered with a cap for prevention of hypothermia [13]. This result could be explained by the negligence of midwives on the activities of communication for behavior change concerning the delivery plan during antenatal consultations.

Early breastfeeding was performed in only $49 \%$ of newborns. Our results are lower than a study conducted in Uganda in 2015 by Waiswa, et al. who found $72.6 \%$ [10]. Usually, it is when the mother is on the delivery table that the newborn gets it's first feeding, which must be done within an hour. This is due to a lack of support for mothers by midwives and birth attendants who are often very busy with the enormous workload. It is also because mothers and health providers didn't really understand the advantage of the first breastfeeding.

\section{Data on the delivery room}

The delivery room allowed the entry of drafts in $60 \%$ of cases, this rate is higher than Salimata A Diaw's who had found that the delivery room allowed the entry of drafts to $50 \%$ of cases [14]. This could be explained by the non-closing of doors and windows. The delivery room is the place that is supposed to welcome the newborn for the first time. Therefore, it must be appropriate to close doors and windows and avoid drafts.

Complete equipment for the asepsis of the hands (towels, soap) of the birth attendant was not present among all health workers in the two hospitals observed. Sidibe $T$ and his al had found that the quality of the services provided by midwives and birth attendants during childbirth is often mediocre because, according to them, hand washing was not systematic [15]. This could be justified by the fact that midwives forgot most of the time the particular importance on hand washing in delivering room.

The measures concerning newborn care were generally well known to the providers surveyed. According to drying the newborn, $100 \%$ of providers felt that the benefit of drying the newborn immediately after childbirth is to protect him against hypothermia. Koffi and al had already observed good practice on community drying in the prefecture of Kloto in Togo [16]. This result shows that the providers knew the importance of drying the newborn.

Providers had stated that the newborn's first bath should be done six hours after childbirth (except for newborns born to mothers who test positive for HIV).

All providers argued that early breastfeeding should be done within sixteen minutes after birth. But during survey, only $49 \%$ of newborns have benefited an early breastfeeding. Providers do not teach mothers how to breastfeed their newborns; and they do not organize discussion sessions to explain the best practices of breastfeeding. Mothers need to be assisted and accompanied in the initiation of breastfeeding.

\section{Conclusion}

There is variability in the practice of ENC practices in different centers. The improvement of ENC practices in the different centers is one of the best ways to reduce newborn mortality in the municipality. Most of these ENC were provided by midwives. The difficulties related to the newborn care at birth include: the delivery room (inadequacy in relation to the entry of drafts) and hand washing. Those providing newborn care had good knowledge but poor in practice related to newborn care at birth.

\section{Conflict of Interest}

None.

\section{Acknowledgements}

We would like to thank Misses Edoh R and Sakran Eland Tchalem P of National School of Midwives of Kara for their participation in collecting data used to carry out this study.

\section{References}

1. Beck D, Ganges F, Goldman S, Long P (2004) Soins aux nouveaux-nés: Manuel de référence. Saving Newborn Lives, Save the children, 270.

2. Organisation mondiale de la Santé (2014)'Bureau régional du Pacifique occidental. Premiers soins essentiels au nouveau-né. Guide de poche de pratique clinique. Bureau régional de l'OMS pour le Pacifique occidental.

3. Organisation Mondiale de la Santé (2020) Nouveau-nés: améliorer leur survie et leur bien-être.

4. Carlo WA, Goudar SS, Jehan I, Chomba E, Tshefu A, et al. (2010) Newborn-care training and perinatal mortality in developing countries. N Engl J Med 362: 614-623.

5. Ministère de la Planification, du Développement et de l'Aménagement du Territoire (MPDAT) (2015) Ministère de la Santé (MS), et ICF International. Enquête Démographique et de Santé au Togo 2013-2014. Rockville, Maryland, USA: MPDAT, MS et ICF International, 539.

6. Agbéko $F$, Tchagbèlè $O B, A z o u m a h ~ K D$, Ségbédji $K A R$, Djadou KE, et al. (2017) Impact du renforcement de compétences en soins essentiels du nouveau-né sur les connaissances des professionnels de santé au Togo. J Afr Pediatr Genet Med N³: 10-16.

7. Moussa KAMISSOKO (2010) Etat des lieux de l'approche des soins essentiels au nouveau-né et son impact sur la morbidité et la mortalité néonatale dans le district sanitaire de Baroueli, Bamako. Thèse Médecine 69.

8. Zafar AA, Ehiri JE, Anyanwu EC (2003) Use of antenatal services in Kampung District, Cambodia. Scientific World Journal 3: 1081-1092.

9. Sy HS, Goldman S (2005) Manuel technique de base: Soins essentiels aux nouveau-nés. Sénégal, février.

10. Waiswa P, Pariyo G, Kallander K, Akuze J, Namazzi G, et al. (2015) Effect of the Uganda newborn study on careseeking and care practices: A cluster-randomised controlled trial. Glob Health Action 8: 24584.

11. WHO Immediate KMC Study Group (2021) Immediate "Kangaroo mother care and survival of infants with low birth weight. N Engl J Med 384: 2028-2038. 
12. Faye PM, Thiongane A, Diagne-Guéye NR, Ba A, Guéye $M$, et al. (2016) Les soins Kangourou pour nouveau-nés de faible poids de naissance au centre hospitalier national d'enfants Albert-Royer de Dakar. Arch Pediatr 23: 268-274.

13. Diarra S (2009) Soins immédiats du nouveau-né dans le District de Bamako. Thèse Médecine 98.

14. Diaw SA (2015) Pratique des soins essentiels aux nouveaunés dans les centres de santé de la commune I du district de Bamoko. Thèse de médecine, Faculté de médecine et d'odontostomatologie, Mali.
15. Sidibé T, Diarra A, Diallo FSD (2002) Analyse de la situation du nouveau-né au Mali, Sauver la vie du nouveau-né, une initiative de Save The Chidren /USA. Bamako 115.

16. Koffi KS, Balaka $B$, Agbo A, Agbèrè $A D$, Gbadoe $A D$, et al. (2012) Soins traditionnels donnés aux nouveau-nés et nourrissons dans le district sanitaire de Kloto (Togo): Risques et avantages. J Rech Sci Univ Lomé 14: 27-37. 